\title{
Pooled analysis of Swedish case-control studies during 1997-2003 and 2007-2009 on meningioma risk associated with the use of mobile and cordless phones
}

\author{
MICHAEL CARLBERG and LENNART HARDELL \\ Department of Oncology, Faculty of Medicine and Health, Örebro University, SE-701 82 Örebro, Sweden
}

Received March 11, 2015; Accepted April 6, 2015

DOI: $10.3892 / o r .2015 .3930$

\begin{abstract}
A pooled analysis of two case-control studies on meningioma with patients diagnosed during 1997-2003 and 2007-2009 was conducted. Both genders were included, aged 20-80 and 18-75 years, respectively, at the time of diagnosis. Population-based controls, matched according to age and gender, were enrolled. Exposure was assessed by questionnaire. In the entire study, cases with all brain tumor types were included. The whole reference group was used in the unconditional logistic regression analysis on meningioma, with adjustments for gender, age, year of diagnosis and socioeconomic index (SEI). In total, 1,625 meningioma cases and 3,530 controls were analyzed. Overall no association with use of mobile or cordless phones was found. In the fourth quartile of use $(>1,436 \mathrm{~h})$ somewhat increased risk was found for mobile phones yielding an odds ratio $(\mathrm{OR})=1.2,95 \%$ confidence intervals $(\mathrm{CI})=0.9-1.6$ and cordless phones $\mathrm{OR}=1.7$, 95\% $\mathrm{CI}=1.3-2.2$. Higher risk was calculated in the highest decile $(>3,358 \mathrm{~h}), \mathrm{OR}=1.5,95 \% \mathrm{CI}=0.99-2.1$ and $\mathrm{OR}=2.0,95 \%$ $\mathrm{CI}=1.4-2.8$, respectively. In addition, the longest latency time gave somewhat increased risk for both phone types although the result was not statistically significant. There was no association for ipsilateral use or anatomical tumor location. The present study showed a somewhat increased risk among heavy users of mobile and cordless phones. Since meningioma is generally a slow-growing tumor, longer latency period is necessary for definitive conclusions.
\end{abstract}

\section{Introduction}

Meningioma is most common among middle-aged and elderly individuals. The incidence is approximately 2 -fold higher

Correspondence to: Michael Carlberg, Department of Oncology, Faculty of Medicine and Health, Örebro University, SE-701 82 Örebro, Sweden

E-mail: michael.carlberg@regionorebrolan.se

Key words: meningioma, mobile phones, cordless phones, wireless phones, radiofrequency fields in women than in men $(1,2)$. It accounts for approximately $30 \%$ of intracranial tumors (3) and develops from the pia and arachnoid membrane that cover the central nervous system. Meningioma is a benign, encapsulated, well-demarked and seldom malignant tumor. It is slow growing and presents with neurological symptoms by compression of adjacent structures. Headaches and seizures are common symptoms.

The only well-established risk factor is ionizing radiation with a long latency period (time from first exposure until diagnosis) encompassing decades $(4,5)$. Sex hormones may be of importance due to the female predominance, yet the role is unclear and has been suggested not to fully explain the higher incidence in women (6).

During recent years, the use of wireless phones has been discussed as a risk factor for brain tumors. When used they emit radiofrequency electromagnetic fields (RF-EMFs).

The Nordic countries were among the first in the world to widely adopt this technology. Analogue phones (NMT; Nordic Mobile Telephone System) were introduced in the early 1980's using both 450 and 900 megahertz (MHz) frequencies. NMT 450 was used in Sweden from 1981 but was shut down on December 31 in 2007; NMT 900 operated during 1986-2000.

The digital system (GSM; Global System for Mobile Communication) using dual band, 900 and $1,800 \mathrm{MHz}$, started to operate in 1991. The third generation of mobile phones, $3 \mathrm{G}$ or Universal Mobile Telecommunication System (UMTS), using 1,900/2,100 MHz RF fields has been introduced worldwide in recent years, and in Sweden in 2003 and currently dominates the market.

Desktop cordless phones (DECT) have been used in Sweden since 1988, first using analogue 800-900 MHz RF fields, but since the early 1990 's using a digital $1,900-\mathrm{MHz}$ system. The cordless phones are becoming more common than traditional telephones connected to landlines. In addition, these phones emit RF-EMF radiation similar to that of mobile phones.

Since the use of this technology is widespread, even a small effect on health would be of concern for the general population. In order to evaluate the carcinogenic effect of RF-EMF on humans, a meeting took place on May 24-31 in 2011 at the International Agency for Research on Cancer (IARC) at WHO in Lyon, France. RF-EMFs from mobile phones, and 
from other devices that emit similar non-ionizing electromagnetic fields in the frequency range from $30 \mathrm{kHz}$ to $300 \mathrm{GHz}$, were categorized as group 2B, i.e., a 'possible', human carcinogen $(7,8)$. The IARC decision on mobile phones was based mainly on results for glioma and acoustic neuroma in case-control studies from the Hardell group in Sweden (9-11) and the IARC Interphone study (12).

Regarding meningioma, the IARC Working Group found that the available evidence was insufficient to reach a conclusion on an association with mobile phone use (7). The only studies that provided results for a 10-year latency or more were those from the Hardell group $(9,13)$ and the Interphone study group (12).

The results for meningioma as well as for other types of brain tumors are, to date, based on limited numbers of long-term users since the technology is fairly new with low numbers of long-term users. In Sweden, the major increase in use (minutes of outgoing calls) and exposure to radiation fields from these phones (not merely access or ownership) in the general population is most evident after 2003 (14).

In order to base the results on a larger material, we now pooled our results on meningioma during the years 1997 2003 and 2007-2009. The same methods were used for both time periods. The Ethics Committee approved the present study.

\section{Materials and methods}

Six administrative regions register new cancer cases covering the entire country of Sweden. Benign brain tumors are also reported to these registries. During 1997-2003, cases and controls in our studies covered central Sweden (9), whereas the 2007-2009 study included the entire country (15). Both men and women with histopathological verification of brain tumors were included in the studies. They were aged 20-80 years (1997-2003) and 18-75 years (2007-2009) at the time of diagnosis. Only living cases were enrolled after permission from the responsible physician. Tumor localization in the brain was based on reports to the cancer registries and medical records, which were obtained after informed consent from the patients.

Controls were ascertained from the Swedish Population Registry that covers the entire country and is continuously updated. A unique ID number can be used to trace each person. The registry also records the present address. For each case, one control subject of the same gender and in the same 5-year group was drawn at random from this registry. They were assigned the same year for cut-off of all exposure as the diagnosis of the respective case.

Exposure was assessed using a mailed questionnaire sent to each person. Regarding use of a mobile phone, the time of average use (min per day) was estimated. The type of mobile phone was recorded and checked by the prefix for the phone number; 010 for analogue and 07 for digital phones $(2 \mathrm{G}, 3 \mathrm{G})$.

Specific questions covered the extent of use in a car with an external antenna, and use of a hands-free device, both regarded as no exposure to RF-EMFs. The ear mostly used during phone calls, or if equally both ears, was also noted.

Use of cordless desktop phones was covered using similar questions; years, average daily use, use of a hands-free device, and preferred ear. Use of the wireless phone was referred to as ipsilateral ( $\geq 50 \%$ of the time) or contralateral $(<50 \%$ of the time) in relation to tumor side. The same method was also applied for the control group; the subjects were assigned the same 'tumor' side as the respective case to the matched control.

The questionnaire also contained a number of questions relating to the overall working history, exposure to different chemicals and other agents, smoking habits, X-ray investigations of the head and neck, and heredity traits for cancer. These other exposure factors will be published separately for the entire study period. When questionnaire answers were unclear, they were resolved by phone using trained interviewers. Thereby, a written protocol was used for clarification of each question. The interviewer supplemented the entire questionnaire during the phone call. Each questionnaire received a unique ID-number that did not disclose whether it was a case or a control; i.e., the interviewer was unaware of the status during further data processing. All information was coded and entered into a database. Case or control status was not disclosed until statistical analyses were undertaken.

Statistical methods. Stata/SE 12.1 (Stata/SE 12.1 for Windows; StataCorp., College Station, TX, USA) was used for all analyses. Odds ratios (OR) and 95\% confidence intervals (CI) were calculated using unconditional logistic regression including the whole control sample (i.e., matched to both malignant and benign cases) to increase the power of the study.

Latency (time from first use) was defined as the year of first use of a wireless phone to the year of diagnosis (the same years being used for the matched control). Cumulative number of hours of use was calculated multiplying the number of years by average time per year based on use per day. Use in a car with external antenna was disregarded, as was use of a handsfree device. A minimum latency period of $\leq 1$ year of exposure was adopted; less than this time was included in the unexposed category. The same year as that for each case's diagnosis was used for the corresponding control as cut-off for exposure accumulation. Note that the latency time was counted from the first use of the specific telephone type or combination of phones; for instance, a mobile phone user may have previously used a cordless phone.

Adjustment was made for the matching variables gender, age (as a continuous variable) and year of diagnosis. It was also made for socio-economic index (SEI) divided into 4 categories (blue-collar and white-collar worker, self-employed and unemployed), since Preston-Martin and Mack previously reported an association between white-collar work and brain tumors (16). Latency was analyzed using 6 time periods; $>1-5$ years, $>5-10$ years, $>10-15$ years, $>15-20$ years, $>20-25$ years and $>25$ years.

Cumulative use of the different phone types and combinations was analyzed in quartiles based on the distribution of total use of wireless phones among the controls. Latency and cumulative use were also analyzed as continuous variables (per year of latency and per $100 \mathrm{~h}$ of cumulative use) to further explore dose-response relationships. Laterality was analyzed for all phone types separately but not for the whole group of wireless phone users, since the side could differ for mobile and cordless phone use by the same person. 
Table I. Odds ratio and $95 \%$ confidence interval for the meningioma cases $(n=1,625)$ in regards to the use of mobile and cordless phones in the different latency groups.

\begin{tabular}{|c|c|c|c|c|c|}
\hline Latency & $\begin{array}{l}\text { Analogue } \\
\text { OR }(\mathrm{CI}) \\
(\mathrm{Ca} / \mathrm{Co})\end{array}$ & $\begin{array}{c}\text { Mobile phone, } \\
\text { digital }(2 \mathrm{G}, 3 \mathrm{G}) \\
\mathrm{OR}(\mathrm{CI}) \\
(\mathrm{Ca} / \mathrm{Co})\end{array}$ & $\begin{array}{c}\text { Mobile phone, total } \\
\text { OR }(\mathrm{CI}) \\
(\mathrm{Ca} / \mathrm{Co})\end{array}$ & $\begin{array}{l}\text { Cordless phone } \\
\text { OR }(\mathrm{CI}) \\
(\mathrm{Ca} / \mathrm{Co})\end{array}$ & $\begin{array}{l}\text { Wireless phone } \\
\text { OR }(\mathrm{CI}) \\
(\mathrm{Ca} / \mathrm{Co})\end{array}$ \\
\hline Total, $>1$ year & $\begin{array}{c}1.2(0.9-1.5) \\
(221 / 558)\end{array}$ & $\begin{array}{c}1.0(0.8-1.2) \\
(904 / 2,019)\end{array}$ & $\begin{array}{c}1.0(0.9-1.2) \\
(956 / 2,148)\end{array}$ & $\begin{array}{c}1.1(0.9-1.3) \\
(817 / 1,724)\end{array}$ & $\begin{array}{c}1.0(0.9-1.2) \\
(1,117 / 2,472)\end{array}$ \\
\hline$>1-5$ years & $\begin{array}{c}1.1(0.7-1.7) \\
(32 / 87)\end{array}$ & $\begin{array}{c}1.0(0.8-1.2) \\
(303 / 719)\end{array}$ & $\begin{array}{c}1.0(0.8-1.2) \\
(285 / 674)\end{array}$ & $\begin{array}{c}1.0(0.8-1.2) \\
(277 / 653)\end{array}$ & $\begin{array}{c}0.9(0.8-1.1) \\
(290 / 748)\end{array}$ \\
\hline$>5-10$ years & $\begin{array}{c}1.1(0.8-1.6) \\
(50 / 137)\end{array}$ & $\begin{array}{c}1.0(0.8-1.2) \\
(306 / 659)\end{array}$ & $\begin{array}{c}1.1(0.8-1.3) \\
(325 / 688)\end{array}$ & $\begin{array}{c}1.2(0.9-1.4) \\
(321 / 655)\end{array}$ & $\begin{array}{c}1.1(0.9-1.4) \\
(379 / 767)\end{array}$ \\
\hline$>10-15$ years & $\begin{array}{c}1.1(0.7-1.7) \\
(42 / 113)\end{array}$ & $\begin{array}{c}1.0(0.8-1.4) \\
(220 / 471)\end{array}$ & $\begin{array}{c}1.1(0.8-1.4) \\
(210 / 476)\end{array}$ & $\begin{array}{c}1.2(0.9-1.6) \\
(151 / 294)\end{array}$ & $\begin{array}{c}1.1(0.9-1.4) \\
(268 / 578)\end{array}$ \\
\hline$>15-20$ years & $\begin{array}{c}1.4(0.9-2.2) \\
(50 / 107)\end{array}$ & $\begin{array}{c}1.0(0.7-1.4) \\
(75 / 170)\end{array}$ & $\begin{array}{c}1.1(0.8-1.5) \\
(89 / 196)\end{array}$ & $\begin{array}{c}1.2(0.8-1.8) \\
(61 / 109)\end{array}$ & $\begin{array}{c}1.2(0.9-1.6) \\
(126 / 253)\end{array}$ \\
\hline$>20-25$ years & $\begin{array}{c}1.0(0.6-1.8) \\
(31 / 81)\end{array}$ & $(0 / 0)$ & $\begin{array}{c}1.0(0.6-1.6) \\
(31 / 81)\end{array}$ & $\begin{array}{c}1.3(0.5-3.5) \\
(7 / 13)\end{array}$ & $\begin{array}{c}1.0(0.7-1.6) \\
\quad(38 / 93)\end{array}$ \\
\hline$>25$ years & $\begin{array}{c}1.4(0.7-2.9) \\
(16 / 33)\end{array}$ & $\begin{array}{c}- \\
(0 / 0)\end{array}$ & $\begin{array}{c}1.3(0.7-2.5) \\
(16 / 33)\end{array}$ & $\begin{array}{c}- \\
(0 / 0)\end{array}$ & $\begin{array}{c}1.3(0.7-2.5) \\
(16 / 33)\end{array}$ \\
\hline
\end{tabular}

Numbers of exposed cases (Ca) and controls (Co) are provided. Adjustment was made for age at diagnosis, gender, SEI-code and year of diagnosis. OR, odds ratio; $\mathrm{CI}$, confidence interval.

Table II. Odds ratio and $95 \%$ confidence interval for meningioma per $100 \mathrm{~h}$ of cumulative use and per year of latency.

\begin{tabular}{|c|c|c|c|c|}
\hline & \multicolumn{2}{|c|}{$\begin{array}{l}\text { Per } 100 \mathrm{~h} \text { of } \\
\text { cumulative use }\end{array}$} & \multicolumn{2}{|c|}{$\begin{array}{l}\text { Per year of } \\
\text { latency }\end{array}$} \\
\hline & OR & $95 \% \mathrm{CI}$ & OR & $95 \% \mathrm{CI}$ \\
\hline Analogue & 1.019 & $1.003-1.035$ & 1.009 & $0.992-1.027$ \\
\hline $\begin{array}{l}\text { Mobile phone, } \\
\text { digital }(2 \mathrm{G}, 3 \mathrm{G})\end{array}$ & 1.005 & $1.0001-1.010$ & 1.002 & $0.983-1.021$ \\
\hline $\begin{array}{l}\text { Mobile phone, } \\
\text { total }\end{array}$ & 1.005 & $1.001-1.009$ & 1.006 & $0.992-1.020$ \\
\hline Cordless phone & 1.010 & $1.005-1.014$ & 1.016 & $0.999-1.033$ \\
\hline Wireless phone & 1.006 & $1.003-1.009$ & 1.010 & $0.996-1.023$ \\
\hline
\end{tabular}

Adjustment was made for age at diagnosis, gender, SEI-code and year of diagnosis. OR, odds ratio; CI; confidence internal.

\section{Results}

Numbers. In total, 2,349 cases with a benign tumor were included for the study periods $1997-2003$ and 2007-2009. Of these subjects 2,068 (88\%) participated. Most of these cases had a diagnosis of meningioma $(n=1,625)(79 \%)$, and 431 were men and 1,194 women. The mean age was 57 years (median 57 and range 20-80).

Of the 4,038 controls, 3,530 (87\%) participated (1,492 men and 2,038 women). The mean age was 54 years (median 55 and range 19-80).
Overall results and latency. The median latency time for use of mobile phones in the meningioma cases was 9.0 years (mean 9.4 and range 2-28). The corresponding results for cordless phones were a median of 8.0 years (mean 8.2 and range 2-21). Mean cumulative mobile phone use for the cases was $881 \mathrm{~h}$ (median 176 and range 1-33,215) and for controls $784 \mathrm{~h}$ (median 192 and range 1-19,756). Regarding cordless phone use, the mean cumulative time for cases was $1,309 \mathrm{~h}$ (median 487 and range 3-58,400) and for controls $861 \mathrm{~h}$ (median 365 and range 1-18,980).

The results are shown in Table I for meningioma and the use of wireless phones in the different latency groups. Analogue phones gave $\mathrm{OR}=1.2,95 \% \mathrm{CI}=0.9-1.5$ and $\mathrm{OR}=1.4$, $95 \% \mathrm{CI}=0.7-2.9$ in the longest latency group of $>25$ years.

Use of digital mobile phones (2G and/or $3 \mathrm{G})$ gave overall $\mathrm{OR}=1.0,95 \% \mathrm{CI}=0.8-1.2$ with a somewhat higher $\mathrm{OR}$ in the longest latency interval $>15-20$ years although not statistically significant.

Use of cordless phones produced $\mathrm{OR}=1.1,95 \% \mathrm{CI}=0.9-1.3$ increasing to $\mathrm{OR}=1.3,95 \% \mathrm{CI}=0.5-3.5$ in the longest latency group.

The group of total wireless phone use (mobile and/or cordless phone) gave similar results as for the mobile and cordless phones separately, without any statistically significant results. Regarding OR per additional year of latency, OR increased somewhat but the difference was not statistically significant (Table II).

Tumor localization and laterality. We also analyzed the risk for different anatomical localizations of meningioma. Use of wireless phones yielded for the temporal lobe $(n=468) \mathrm{OR}=1.1$, $95 \% \mathrm{CI}=0.8-1.4$. With latency $>25$ years the OR increased to 
Table III. Odds ratio and 95\% confidence interval for meningioma, total, ipsilateral and contralateral exposure.

\begin{tabular}{|c|c|c|c|c|c|c|c|c|c|}
\hline & \multicolumn{3}{|c|}{ All } & \multicolumn{3}{|c|}{ Ipsilateral } & \multicolumn{3}{|c|}{ Contralateral } \\
\hline & $\mathrm{Ca} / \mathrm{Co}$ & OR & $95 \% \mathrm{CI}$ & $\mathrm{Ca} / \mathrm{Co}$ & OR & $95 \% \mathrm{CI}$ & $\mathrm{Ca} / \mathrm{Co}$ & OR & $95 \% \mathrm{CI}$ \\
\hline Analogue & $221 / 558$ & 1.2 & $0.9-1.5$ & $106 / 252$ & 1.2 & $0.8-1.6$ & $75 / 184$ & 1.1 & $0.8-1.6$ \\
\hline Mobile phone, digital $(2 \mathrm{G}, 3 \mathrm{G})$ & $904 / 2,019$ & 1.0 & $0.8-1.2$ & $434 / 869$ & 1.1 & $0.9-1.4$ & $329 / 684$ & 1.0 & $0.8-1.3$ \\
\hline Mobile phone, total & $956 / 2,148$ & 1.0 & $0.9-1.2$ & $459 / 920$ & 1.2 & $0.9-1.5$ & $342 / 729$ & 1.0 & $0.8-1.3$ \\
\hline Cordless phone & $817 / 1,724$ & 1.1 & $0.9-1.3$ & $378 / 766$ & 1.1 & $0.9-1.4$ & $290 / 565$ & 1.0 & $0.8-1.3$ \\
\hline
\end{tabular}

Numbers of exposed cases (Ca) and controls (Co) are provided. Adjustment was made for age at diagnosis, gender, SEI-code and year of diagnosis. Ipsilateral, $\geq 50 \%$ use of the phone on the same side as the tumor was located; contralateral, $<50 \%$ use of the phone on the same side as the tumor was located; tumor laterality not available for 306 cases and 836 controls. OR, odds ratio; CI, confidence interval.

Table IV. Odds ratio and 95\% confidence interval for meningioma $(n=1,625)$ for cumulative use of wireless phones in quartiles based on the use of wireless phones among controls in total.

\begin{tabular}{|c|c|c|c|c|c|}
\hline Quartile & $\begin{array}{l}\text { Analogue } \\
\text { OR (CI) } \\
(\mathrm{Ca} / \mathrm{Co})\end{array}$ & $\begin{array}{l}\text { Mobile phone, digital } \\
\qquad \begin{array}{c}(2 \mathrm{G}, 3 \mathrm{G}) \\
\mathrm{OR}(\mathrm{CI}) \\
(\mathrm{Ca} / \mathrm{Co})\end{array}\end{array}$ & $\begin{array}{c}\text { Mobile phone, total } \\
\text { OR }(\mathrm{CI}) \\
(\mathrm{Ca} / \mathrm{Co})\end{array}$ & $\begin{array}{c}\text { Cordless phone } \\
\text { OR }(\mathrm{CI}) \\
(\mathrm{Ca} / \mathrm{Co})\end{array}$ & $\begin{array}{c}\text { Wireless phone } \\
\text { OR }(\mathrm{CI}) \\
(\mathrm{Ca} / \mathrm{Co})\end{array}$ \\
\hline First quartile & $\begin{array}{c}1.1(0.8-1.5) \\
(121 / 304)\end{array}$ & $\begin{array}{c}1.0(0.8-1.2) \\
(408 / 878)\end{array}$ & $\begin{array}{c}1.0(0.8-1.2) \\
(430 / 920)\end{array}$ & $\begin{array}{c}1.0(0.8-1.2) \\
(183 / 478)\end{array}$ & $\begin{array}{c}1.0(0.8-1.1) \\
(270 / 641)\end{array}$ \\
\hline Second quartile & $\begin{array}{c}1.2(0.9-1.8) \\
(59 / 146)\end{array}$ & $\begin{array}{c}1.1(0.8-1.4) \\
(215 / 459)\end{array}$ & $\begin{array}{c}1.1(0.9-1.4) \\
(227 / 492)\end{array}$ & $\begin{array}{c}1.0(0.8-1.3) \\
(229 / 534)\end{array}$ & $\begin{array}{c}1.0(0.8-1.2) \\
(252 / 596)\end{array}$ \\
\hline Third quartile & $\begin{array}{c}1.0(0.6-1.7) \\
(26 / 82)\end{array}$ & $\begin{array}{c}0.9(0.7-1.2) \\
(144 / 394)\end{array}$ & $\begin{array}{c}0.9(0.7-1.2) \\
(151 / 416)\end{array}$ & $\begin{array}{c}1.0(0.8-1.3) \\
(205 / 451)\end{array}$ & $\begin{array}{c}1.0(0.8-1.2) \\
(259 / 617)\end{array}$ \\
\hline Fourth quartile & $\begin{array}{c}1.8(0.9-3.6) \\
(15 / 26)\end{array}$ & $\begin{array}{c}1.2(0.9-1.6) \\
(137 / 288)\end{array}$ & $\begin{array}{c}1.2(0.9-1.6) \\
(148 / 320)\end{array}$ & $\begin{array}{c}1.7(1.3-2.2) \\
(200 / 261)\end{array}$ & $\begin{array}{c}1.3(1.1-1.6) \\
(336 / 618)\end{array}$ \\
\hline p-trend & 0.46 & 0.18 & 0.19 & $<0.0001$ & 0.01 \\
\hline
\end{tabular}

Numbers of exposed cases $(\mathrm{Ca})$ and controls $(\mathrm{Co})$ are provided. Adjustment was made for age at diagnosis, gender, SEI-code and year of diagnosis . First quartile 1-122 h; second quartile 123-511 h; third quartile 512-1,486 h; fourth quartile >1,486 h. OR, odds ratio; CI, confidence interval.

$1.4,95 \% \mathrm{CI}=0.5-4.0$. No statistically significant increased or decreased OR was found in any latency group for any phone type (data not shown). The results were similar for meningioma in the frontal lobe $(n=736)$ or other localizations $(n=324)$ with no pattern of an association. Note that tumor localization was missing for some cases $(n=60)$, and not given for midline tumors or multiple localizations $(n=37)$.

Ipsilateral mobile phone use produced $\mathrm{OR}=1.2,95 \%$ $\mathrm{CI}=0.9-1.5$, whereas contralateral use gave $\mathrm{OR}=1.0,95 \%$ $\mathrm{CI}=0.8-1.3$ (Table III). Similar results were found for cordless phone use. We also analyzed laterality of mobile and cordless phone use in the different latency periods without any pattern of an association (data not shown).

Cumulative use. As documented in Table IV, the cumulative use in quartiles is displayed. No statistically significant trend was found for mobile phones although somewhat increased risk was obtained for cumulative use in the fourth quartile $>1,486 \mathrm{~h}$ with $\mathrm{OR}=1.2,95 \% \mathrm{CI}=0.9-1.6$ (p-trend $=0.19$ ). Cordless phone use gave statistically significant increased risk in the fourth quartile to $\mathrm{OR}=1.7,95 \% \mathrm{CI}=1.3-2.2$ (p-trend <0.0001). Total use of wireless phones $>1,486 \mathrm{~h}$ gave $\mathrm{OR}=1.3,95 \% \mathrm{CI}=1.1-1.6$
( $\mathrm{p}$-trend $=0.01$ ). We also analyzed the $>90$ th percentile corresponding to $>3,358 \mathrm{~h}$ cumulative use. Mobile phones of the digital type ( $2 \mathrm{G}$ and $3 \mathrm{G}$ ) gave a borderline increased risk with $\mathrm{OR}=1.5,95 \% \mathrm{CI}=1.0005-2.3$ (p-trend $=0.045$ ) and cordless phone gave $\mathrm{OR}=2.0,95 \% \mathrm{CI}=1.4-2.8$ (p-trend $<0.0001$; data not shown). The results for analogue mobile phones were based on only 6 exposed cases and 8 exposed controls yielding $\mathrm{OR}=2.1,95 \% \mathrm{CI}=0.7-6.3$ (p-trend $=0.65$ ).

Somewhat increased risk was found for the different phone types per 100-h cumulative use (Table II). Mobile phone use in total gave $\mathrm{OR}=1.005,95 \% \mathrm{CI}=1.001-1.009$ and cordless phone use $\mathrm{OR}=1.010,95 \% \mathrm{CI}=1.005-1.014$.

Age groups. We analyzed mobile phone use in total and cordless phone use in 3 different age groups for the first use; $<20$ years, 20-49 years, and $>50$ years. The analyses included also ipsilateral and contralateral use. No statistically significant increased or decreased risks were found (data not shown).

Multivariate and conditional logistic regression analysis. Results are documented in Table $\mathrm{V}$ for multivariate analysis of cumulative use and per year of latency adjusted for years of 
Table V. Odds ratio and $95 \%$ confidence interval for meningioma per $100 \mathrm{~h}$ cumulative use in a multivariate analysis, and per year of latency adjusted for years of use of any mobile or cordless phone prior to the respective type.

\begin{tabular}{|c|c|c|c|c|}
\hline & \multicolumn{2}{|c|}{$\begin{array}{c}\text { Per } 100 \mathrm{~h} \text { of } \\
\text { cumulative use }\end{array}$} & \multicolumn{2}{|c|}{$\begin{array}{l}\text { Per year } \\
\text { of latency }\end{array}$} \\
\hline & OR & $95 \% \mathrm{CI}$ & OR & $95 \% \mathrm{CI}$ \\
\hline Analogue & 1.014 & $0.998-1.030$ & 1.009 & $0.991-1.027$ \\
\hline $\begin{array}{l}\text { Mobile phone, } \\
\text { digital ( } 2 \mathrm{G}, 3 \mathrm{G})\end{array}$ & 1.002 & 0.996-1.007 & 1.001 & $0.982-1.020$ \\
\hline Cordless phone & 1.009 & $1.004-1.013$ & 1.017 & $0.999-1.034$ \\
\hline
\end{tabular}

In all calculations adjustment was made for age at diagnosis, gender, SEI-code and year of diagnosis. OR, odds ratio; CI, confidence interval.

use of any mobile or cordless phone before the respective type. The risk increased with statistical significance for cordless phone use with $\mathrm{OR}=1.009,95 \% \mathrm{CI}=1.004-1.013$ per 100 -h use. The risk per year of latency was not statistically significantly increased for any wireless phone type.

We also used conditional logistic regression analysis to examine whether dissolving of the matching had an impact on the results. This produced overall for mobile phone use $\mathrm{OR}=1.0,95 \% \mathrm{CI}=0.8-1.2$ vs. $\mathrm{OR}=1.0,95 \% \mathrm{CI}=0.9-1.2$ in the unconditional regression analysis. The corresponding results for cordless phones were $\mathrm{OR}=1.0,95 \% \mathrm{CI}=0.9-1.2$ vs. $\mathrm{OR}=1.1$, $95 \% \mathrm{CI}=0.9-1.3$, and for wireless phones in total $\mathrm{OR}=1.0,95 \%$ $\mathrm{CI}=0.8-1.1$ vs. $\mathrm{OR}=1.0,95 \% \mathrm{CI}=0.9-1.2$ (data not shown).

\section{Discussion}

Main findings. The main result of the present study was that no overall association was noted between use of wireless phones and meningioma. However, a somewhat higher OR was found in the longest latency group, $>25$ years, for use of mobile phones. A similar result was found for use of cordless phones in the latency group $>20-25$ years, the longest time for that phone type. However, these results were not statistically significant and no statistically significant increased OR was calculated per year of latency.

The highest absorption of RF-EMF emissions from a handheld phone is on the same side of the brain (ipsilateral) as the phone is used, with the highest dose in the temporal lobe (17). In the present study, there was no statistically significant association according to laterality or to anatomical localization of meningioma.

The cumulative use of wireless phones in our present study was divided into quartiles depending on cumulative use of wireless phones in total among the controls. A modest increased risk was found in the fourth quartile $>1,486 \mathrm{~h}$ of cumulative use for mobile phones. The result was statistically significant for cordless phones with a statistically significant trend $(\mathrm{p}<0.0001)$. We also analyzed the $>90$ th percentile of cumulative use which gave support for an association with use both of mobile and cordless phones. In the multivariate analysis, only cordless phone use remained as a statistically significant risk factor per $100 \mathrm{~h}$ of cumulative use. The risk increased somewhat per year of latency for all phone types but was not statistically significant. Thus, taking together the results for mobile phones and cordless phones, an increased risk cannot be excluded among the heaviest users.

Strengths and limitations. Cases from the entire country of Sweden with benign brain tumors diagnosed during 1997-2003 and 2007-2009 were included. We included only cases with a histopathological diagnosis of a brain tumor. Hence, we asked the six regional cancer registries not to report cases with only a clinical diagnosis. The reason was that we wanted to get a valid diagnosis of brain tumor for separate analysis depending on the tumor type. If necessary the histopathological reports were supplemented by records from pathology departments around the country after informed consent from the case. It is not probable that exclusion of cases with only a clinical diagnosis would have biased the results, since criteria for diagnosis are not expected to be related to habits of wireless phone use.

An advantage of the present study was the fairly high response rate among both cases and controls. The response rate was $88 \%(n=2,068)$ among the finally included cases with benign brain tumor. Of the controls, $87 \%(n=3,530)$ answered the questionnaire. Lower response rates were obtained in the Interphone Study especially for controls; meningioma cases $78 \%$, range by centre $56-92 \%,(n=2,425)$, and controls $53 \%$, range $42-74 \%,(n=7,658)(12)$. In the recent CERENAT casecontrol study from France, $75 \%$ of the meningioma cases and $45 \%$ of the finally included controls responded (18).

In the unconditional logistic regression analysis, all controls, both to cases with malignant and benign brain tumors, were used so as to maximize the statistical power. This was possible since adjustment was made for the matching variables age, gender, and year of diagnosis. In addition, adjustment was made for the socioeconomic index since an association between white-collar work and brain tumors has been reported (16). We also conducted a conditional logistic regression analysis yielding similar results. Thus, the used statistical method did not bias the results.

Results from other studies. In our previous studies, we only included living cases so as to obtain the best assessment of exposure as possible $(9,10,19)$. Excluding deceased cases may theoretically bias the results, notably if there is no association between use of wireless phones and brain tumor in that patient group or even a protective effect. However, meningioma is a benign tumor with good prognosis so few cases were deceased and thus not included in the study.

Ionizing radiation is an established risk factor for brain tumors, generally more strongly associated with meningioma than with glioma. Among atomic bomb survivors, a greatly increased risk for meningioma has been found, as well as among children with radiation therapy for scalp ringworm (4). In a review of estimated exposure doses to the brain in eight cohort studies, no effect modification on the risk by gender, age at exposure, time since exposure or attained age was observed (5). In a study on radiation-associated tumors following therapeutic cranial radiation, there was a positive association between dose of cranial irradiation and develop- 
ment of meningioma with a mean latency of 21.8 years (20). Average time interval may be dependent on dose, and intervals to tumor appearance of 35, 26 and 19-24 years have been reported for low-, moderate-, and high-dose radiation, respectively (21). Thus, regarding RF-EMF emissions and an association with meningioma, long latency times of decades would be expected, even longer than in the present study.

In Interphone, statistically significant decreased meningioma risk with $\mathrm{OR}=0.79,95 \% \mathrm{CI}=0.68-0.91$ was reported overall (12). No effect modification was found for time since the start of use. With cumulative call time $>1,640 \mathrm{~h}$ the risk increased somewhat to $\mathrm{OR}=1.15,95 \% \mathrm{CI}=0.81-1.62$. We have discussed the many shortcomings in Interphone elsewhere $(22,23)$.

In the French case-control study including the time period 2004-2006, an increased risk was found among the heaviest mobile phone users (18). Thus cumulative use $>896 \mathrm{~h}$ gave $\mathrm{OR}=2.57,95 \% \mathrm{CI}=1.02-6.44$ for meningioma ( $\mathrm{p}$-trend $=0.06$ ). Time since first use $>10$ years yielded $\mathrm{OR}=1.57,95 \%$ $\mathrm{CI}=0.64-3.86$ (p-trend $=0.52$ ), whereas no increased risk was found for shorter time of use. Use of cordless phones was not assessed. The study provided some support of an increased risk for heaviest cumulative use of mobile phones but less clear for latency. Thus, there are some similarities with our findings.

In conclusion, in the present study, no conclusive evidence of an association between use of mobile and cordless phones and meningioma was found. However, an increased risk was noted among heavy users of mobile and cordless phones, especially in the highest decile of cumulative use. The risk increased somewhat with latency, although the result was not statistically significant. Meningioma risk was not associated with tumor localization or ipsilateral use. However, taking the long latency periods that have been reported for the increased meningioma risk associated with exposure to ionizing radiation it remains too early to make a definitive risk assessment. Results for even longer latency periods of wireless phone use than in this study are desirable.

\section{Acknowledgements}

Mr. Brian Stein is acknowledged for general support. The study was supported by grants from the Cancer-och Allergifonden, Cancerhjälpen, Pandora-Foundation for Independent Research, Berlin, Germany, Environmental Health Trust and Kone Foundation, Helsinki, Finland. The authors thank Ms Iréne Larsson for assistance in the data collection and Professor Kjell Hansson Mild for technical advice.

\section{References}

1. Cordera S, Bottacchi E, D'Alessandro G, Machado D, De Gonda F and Corso G: Epidemiology of primary intracranial tumours in NW Italy, a population based study: stable incidence in the last two decades. J Neurol 249: 281-284, 2002.

2. Cea-Soriano L, Wallander MA and García Rodríguez LA: Epidemiology of meningioma in the United Kingdom. Neuroepidemiology 39: 27-34, 2012.

3. Claus EB, Bondy ML, Schildkraut JM, Wiemels JL, Wrensch M and Black PM: Epidemiology of intracranial meningioma. Neurosurgery 57: 1088-1095, 2005.
4. Wiemels J, Wrensch M and Claus EB: Epidemiology and etiology of meningioma. J Neurooncol 99: 307-314, 2010.

5. Braganza MZ, Kitahara CM, Berrington de González A, Inskip PD, Johnson KJ and Rajaraman P: Ionizing radiation and the risk of brain and central nervous system tumors: a systematic review. Neuro Oncol 14: 1316-1324, 2012.

6. Korhonen K, Salminen T, Raitanen J, Auvinen A, Isola J and Haapasalo H: Female predominance in meningiomas can not be explained by differences in progesterone, estrogen, or androgen receptor expression. J Neurooncol 80: 1-7, 2006.

7. Baan R, Grosse Y, Lauby-Secretan B, El Ghissassi F, Bouvard V, Benbrahim-Tallaa L, Guha N, Islami F, Galichet L and Straif K; WHO International Agency for Research on Cancer Monograph Working Group: Carcinogenicity of radiofrequency electromagnetic fields. Lancet Oncol 12: 624-626, 2011.

8. IARC Working Group on the Evaluation of Carcinogenic Risks to Humans: Non-ionizing radiation, part 2: radiofrequency electromagnetic fields. IARC Monogr Eval Carcinog Risks Hum 102: 1-460, 2013.

9. Hardell L, Carlberg M and Hansson Mild K: Pooled analysis of two case-control studies on the use of cellular and cordless telephones and the risk of benign brain tumors diagnosed during 1997-2003. Int J Oncol 28: 509-518, 2006.

10. Hardell L, Carlberg M and Hansson Mild K: Pooled analysis of two case-control studies on use of cellular and cordless telephones and the risk for malignant brain tumors diagnosed in 1997-2003. Int Arch Occup Environ Health 79: 630-639, 2006.

11. Hardell L, Carlberg M and Hansson Mild K: Pooled analysis of case-control studies on malignant brain tumors and the use of mobile and cordless phones including living and deceased subjects. Int J Oncol 38: 1465-1474, 2011.

12. INTERPHONE Study Group: Brain tumour risk in relation to mobile telephone use: results of the INTERPHONE international case-control study. Int J Epidemiol 39: 675-694, 2010.

13. Hardell L and Carlberg M: Mobile phones, cordless phones and the risk for brain tumors. Int J Oncol 35: 5-17, 2009.

14. Post-och Telestyrelsen: Svensk Telemarknad 2010. Stockholm, Sweden: PTS-ER-2011:15. http://statistik.pts. se/pts2012/FILES/RAPPORTER/2010/Telemarknad_2010.pdf. (Accessed, Feb 16, 2015).

15. Carlberg M, Söderqvist F, Hansson Mild K and Hardell L: Meningioma patients diagnosed 2007-2009 and the association with use of mobile and cordless phones: a case-control study. Environ Health 12: 60, 2013.

16. Preston-Martin S and Mack W: Neoplasms of the nervous system. In: Cancer Epidemiology and Prevention. Schottenfeld D and Fraumeni JF (eds). Oxford University Press, New York, NY, pp1231-1281, 1996.

17. Cardis E, Deltour I, Mann S, Moissonnier M, Taki M, Varsier N, Wake K and Wiart J: Distribution of RF energy emitted by mobile phones in anatomical structures of the brain. Phys Med Biol 53: 2771-2783, 2008.

18. Coureau G, Bouvier G, Lebailly P, Fabbro-Peray P, Gruber A, Leffondre K, Guillamo JS, Loiseau H, Mathoulin-Pélissier S, Salamon R, et al: Mobile phone use and brain tumours in the CERENAT case-control study. Occup Environ Med 71: 514-522, 2014.

19. Hardell L, Näsman A, Påhlson A, Hallquist A and Hansson Mild K: Use of cellular telephones and the risk for brain tumors: a case-control study. Int J Oncol 15: 113-116, 1999.

20. Chowdhary A, Spence AM, Sales L, Rostomily RC, Rockhill JK and Silbergeld DL: Radiation associated tumors following therapeutic cranial radiation. Surg Neurol Int 3: 48, 2012.

21. Kleinschmidt-DeMasters BK and Lillehei KO: Radiation-induced meningioma with a 63 -year latency period. Case report. J Neurosurg 82: 487-488, 1995.

22. Hardell L, Carlberg M and Hansson Mild K: Methodological aspects of epidemiological studies on the use of mobile phones and their association with brain tumors. Open Environ Sci 2: 54-61, 2008.

23. Hardell L, Carlberg M and Hansson Mild K: Use of mobile phones and cordless phones is associated with increased risk for glioma and acoustic neuroma. Pathophysiology 20: 85-110, 2013. 